\title{
Quantitative nuclear DNA content in fine needle aspirates of pancreatic cancer
}

\author{
A R Weger, K S Glaser, G Schwab, D Oefner, E Bodner, G U Auer, G Mikuz
}

\begin{abstract}
The quantitative nuclear DNA content of nuclei from fine needle aspirations from 70 patients with pancreatic cancer was measured using an image analyser system. Retrospective analysis of patients indicated that cases with tumour stemlines in the diploid region had the best chance for radical surgery $(p<0.006)$ and the best probability of survival $(p<0.0004)$. The prognosis for patients with tetraploid stemlines was intermediate and was poorest for patients with no stemlines in the diploidtetraploid region. From those parameters assessed postoperatively, only the tumour stage added appreciable information on prognosis to the preoperative quantitative DNA content obtainable. Therefore, in patients with pancreatic cancer the quantitative DNA content should be taken into account in planning treatment and assessing prognosis. Furthermore, the quantitative DNA content may have a major role in stratification for further treatment trials.
\end{abstract}

Cancer of the pancreas has the most dismal prognosis among abdominal malignancies. ${ }^{1}$ Because of both the topographical peculiarities of the pancreas and tumour biology radical resection of tumours at the time of diagnosis is possible in only $10-30 \%$ of cases. ${ }^{2}$ Modern diagnostic methods have improved the preoperative assessment of tumour stage and possible resectability. These are, however, only crude measures of the biological behaviour of tumours and the prognosis for patients with comparable tumour stages.

In most malignant tumours there is a relation between the quantitative DNA content of tumour nuclei and the tumour's aggressiveness..$^{3-6}$ Recent results indicate that the quantitative DNA content is also of prognostic value in pancreatic cancer,' but such results are based on cell preparations from resected specimens. Quantitative DNA measurements of fine needle aspirates of mucoepidermoid cancer and breast cancer provide important preoperative information, as has been previously shown. ${ }^{89}$

The aim of this retrospective study was to use slides of fine needle aspirates from patients with pancreatic cancer for DNA image analysis and to correlate the quantitative DNA content of tumour nuclei with the feasibility of radical surgery and with prognosis.

\section{Methods}

PATIENTS

We investigated archival cytological slides from
70 patients with pancreatic cancer which had been diagnosed between 1976 and 1987. There were 37 women $(52 \cdot 8 \%)$ and 33 men $(47 \cdot 2 \%)$, whose ages at diagnosis ranged from 25 to 85 years (median 68 years, mean 66 years). All but five patients had died, and follow up ranged from 19 to 84 months for the surviving patients. All patients had undergone laparotomy, and the diagnosis of ductal pancreatic cancer was confirmed by histology. Forty eight tumours were located in the head of the pancreas, 17 in the body, and five in the tail. In 31 cases radical surgery of the primary tumour was possible (Whipple's partial duodenocephalopancreatectomy in 26 and left side resection of the pancreas in five), whereas in 39 cases palliative surgery had been performed (bilidigestive anastomosis and gastroenterostomy). The indication for radical surgery was local resectability with absent liver metastases. Tumour extension was stage $I$ in 12 cases (maximal tumour extension to duodenum, bile duct, and peripancreatic tissue); in the other 58 cases the tumour had spread beyond potential cure, to stage $>I$ (II-IV =extension to stomach, spleen, colon, large vessels, regional nodal or distant metastases). ${ }^{10}$ Tumours of the papilla of Vater were not included in the study.

CELL PREPARATION AND STAINING

We used the original wet-fixed, haematoxylin and eosin stained slides, on which the primary diagnosis of ductal cancer of the pancreas had been based two to 13 years earlier. Before the cytochemical procedures were carried out all slides were reviewed by two senior cytopathologists who concurred with the diagnosis and the suitability of the preparations. In the protocol for each slide emphasis was put on the admixture of normal ductal epithelium that could erroneously affect the DNA measurements. The areas on the slides, where cancer cells were identified by cytopathology, were circled in ink and the marking traced with a glass cutter on the bottom of the slide. Of 75 cases of cancer, 70 were eligible for measurement. A slide was classified as eligible when more than 100 tumour cells were scattered on the slide. In order to use this cytological material for image cytometric measurement we used a procedure developed in our laboratory that entailed removing the original haematoxylin and eosin stain in absolute ethanol, refixing in $10 \%$ neutral formalin for a minimum of 15 hours, and subsequent staining by the Feulgen method. ${ }^{811} \mathrm{~A}$ previous study indicated that the destaining technique did not change the DNA distribution pattern and that there is no important difference in the ability of the Feulgen method to stain cells in old specimens compared with fresh specimens. ${ }^{9}$ 


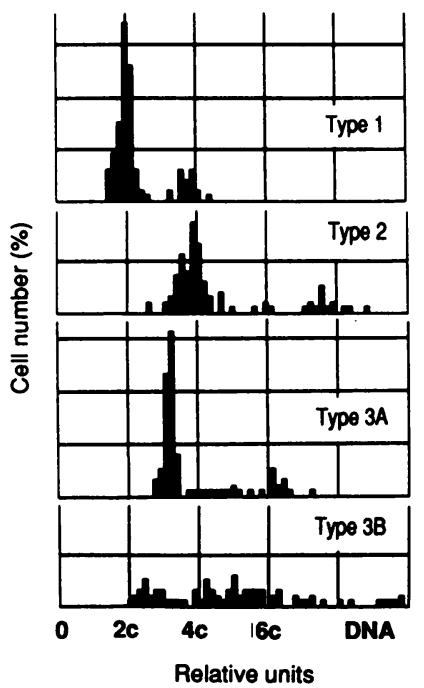

Figure 1: Histogram of three DNA-types (see Methods).

\section{IMAGE ANALYSIS}

Cytometric assessment of the nuclear DNA contents was performed using an image analysis system constructed in collaboration with Dr Olaf Ahrens (Ahrens System, Bargteheide/Hamburg, FRG). By means of this system the integrated optical density of at least 100 tumour nuclei was measured at the absorption maximum for the Feulgen stain, $546 \mathrm{~nm}$. Granulocytes and lymphocytes admixed with the tumour cells on the slides were used as internal control cells in the staining procedure. All tumour values were expressed in relation to their corresponding staining control, which was given the value $2 c$, denoting the normal 'diploid' DNA content. All DNA measurements were performed by the same investigator (ARW) with no previous knowledge of coded clinical data. The histograms were divided into three groups (Fig 1): type 1 with one stemline within the 'diploid' region $(1 \cdot 5-2 \cdot 5 \mathrm{c})$ and a $G 2$ fraction in the 'tetraploid' region; type 2 with a stemline in the 'tetraploid' region $(3 \cdot 5-4 \cdot 5 \mathrm{c})$ and a $\mathrm{G} 2$ fraction in the 'octoploid' region, independent of the presence of a 'diploid' stemline; and type 3 with a stemline outside the 'diploid'/'tetraploid' region or a mosaic (unimodal) pattern. To prevent misinterpretation of $\mathrm{G} 2$ and $S$ phase cells, a minimum of $20 \%$ of the cell population was used as the minimum size of a peak to be calculated as a stemline. The reproducibility of the nuclear DNA distribution patterns in fine needle aspirates from the entire tumour has been shown previously. ${ }^{12} 13$ In this material two smears were measured in each of seven cases and all cases were found to conform.

\section{STATISTICAL ANALYSIS}

All data were entered into a microcomputer (IBM AT) and statistical evaluation was carried out using the SAS statistical package. To establish a relation between the three DNA types with the surgery of the primary tumour and the tumour stage, Fisher's exact probability test (two tailed) was used because some variables occurred infrequently. ${ }^{14}$ For estimation and presentation of survival distribution, the test parameters were first considered one by one,
TABLE I DNA type, type of surgery, observation time and status, and tumour stage of 70 patients, according to DNA type and type of surgery

\begin{tabular}{|c|c|c|c|c|c|}
\hline No & $\begin{array}{l}\text { DNA } \\
\text { type }\end{array}$ & $\begin{array}{l}\text { Type of } \\
\text { surgery }\end{array}$ & $\begin{array}{l}\text { Observation } \\
\text { time } \\
\text { (months) }\end{array}$ & $\begin{array}{l}\text { Observation } \\
\text { status }\end{array}$ & $\begin{array}{l}\text { Tumour } \\
\text { stage }^{10}\end{array}$ \\
\hline 1 & 1 & Radical & 9 & Dead & $>I$ \\
\hline 2 & 1 & Radical & 72 & Dead & $>\mathrm{I}$ \\
\hline 3 & 1 & Radical & 22 & Dead & $>I$ \\
\hline 4 & 1 & Radical & 45 & Alive & $>I$ \\
\hline 5 & 1 & Radical & 17 & Dead & $>I$ \\
\hline 6 & 1 & Radical & 53 & Alive & I \\
\hline 7 & i & Radical & 25 & Dead & I \\
\hline 8 & 1 & Palliative & 10 & Dead & $>I$ \\
\hline 9 & 2 & Radical & 84 & Alive & I \\
\hline 10 & 2 & Radical & 12 & Dead & I \\
\hline 11 & 2 & Radical & 4 & Dead & $>\mathrm{I}$ \\
\hline 12 & 2 & Radical & 8 & Dead & $>I$ \\
\hline 13 & 2 & Radical & 10 & Dead & $>\mathrm{I}$ \\
\hline 14 & 2 & Radical & 14 & Dead & I \\
\hline 15 & 2 & Radical & 18 & Dead & $>\mathrm{I}$ \\
\hline 16 & 2 & Radical & 16 & Dead & I \\
\hline 17 & 2 & Radical & 24 & Alive & I \\
\hline 18 & 2 & Radical & 12 & Dead & $>I$ \\
\hline 19 & 2 & Radical & 17 & Dead & $>\mathrm{I}$ \\
\hline 20 & 2 & Radical & 19 & Alive & I \\
\hline 21 & 2 & Radical & 3 & Dead & $>\mathrm{I}$ \\
\hline 22 & 2 & Radical & 3 & Dead & $>\mathrm{I}$ \\
\hline 23 & 2 & Radical & 46 & Dead & $>\mathrm{I}$ \\
\hline 24 & 2 & Radical & 3 & Dead* & $>\mathrm{I}$ \\
\hline 25 & 2 & Radical & 14 & Dead & $>\mathrm{I}$ \\
\hline 26 & 2 & Palliative & 5 & Dead & $>I$ \\
\hline 27 & 2 & Palliative & 10 & Dead & $>\mathrm{I}$ \\
\hline 28 & 2 & Palliative & 11 & Dead & $>\mathrm{I}$ \\
\hline 29 & 2 & Palliative & 7 & Dead & $>I$ \\
\hline 30 & 2 & Palliative & 1 & Dead & $>I$ \\
\hline 31 & 2 & Palliative & 5 & Dead & $>\mathrm{I}$ \\
\hline 32 & 2 & Palliative & 11 & Dead & $>I$ \\
\hline 33 & 2 & Palliative & 4 & Dead & $>\mathrm{I}$ \\
\hline 34 & 2 & Palliative & 7 & Dead & $>I$ \\
\hline 35 & 2 & Palliative & 4 & Dead & $>\mathrm{I}$ \\
\hline 36 & 2 & Palliative & 8 & Dead & $>\mathrm{I}$ \\
\hline 37 & 2 & Palliative & 8 & Dead & $>\mathrm{I}$ \\
\hline 38 & 2 & Palliative & 12 & Dead & $>I$ \\
\hline 39 & 2 & Palliative & 14 & Dead $^{\star}$ & $>I$ \\
\hline 40 & 2 & Palliative & 18 & Dead & $>\mathrm{I}$ \\
\hline 41 & 2 & Palliative & 3 & Dead & $>\mathrm{I}$ \\
\hline 42 & 2 & Palliative & 22 & Dead* ${ }^{\star}$ & I \\
\hline 43 & 2 & Palliative & 1 & Dead & $>\mathrm{I}$ \\
\hline 44 & 3 & Radical & 24 & Dead & $>\mathrm{I}$ \\
\hline 45 & 3 & Radical & 1 & Dead & $>I$ \\
\hline 46 & 3 & Radical & 7 & Dead & $>I$ \\
\hline 47 & 3 & Radical & 36 & Dead & I \\
\hline 48 & 3 & Radical & 1 & Dead & I \\
\hline 49 & 3 & Radical & 4 & Dead & $>I$ \\
\hline 50 & 3 & Radical & 3 & Dead & $>I$ \\
\hline 51 & 3 & Palliative & 3 & Dead & $>\mathrm{I}$ \\
\hline 52 & 3 & Palliative & 1 & Dead & $>I$ \\
\hline 53 & 3 & Palliative & 11 & Dead $^{\star}$ & $>I$ \\
\hline 54 & 3 & Palliative & 1 & Dead & $>\mathrm{I}$ \\
\hline 55 & 3 & Palliative & 2 & Dead & $>I$ \\
\hline 56 & 3 & Palliative & 9 & Dead & I \\
\hline 57 & 3 & Palliative & 1 & Dead & $>I$ \\
\hline 58 & 3 & Palliative & 2 & Dead & $>I$ \\
\hline 59 & 3 & Palliative & 10 & Dead & $>I$ \\
\hline 60 & 3 & Palliative & 6 & Dead & $>I$ \\
\hline 61 & 3 & Palliative & 5 & Dead & $>I$ \\
\hline 62 & 3 & Palliative & 10 & Dead & $>\mathrm{I}$ \\
\hline 63 & 3 & Palliative & 8 & Dead & $>I$ \\
\hline 64 & 3 & Palliative & 7 & Dead & $>\bar{I}$ \\
\hline 65 & 3 & Palliative & 6 & Dead & $>I$ \\
\hline 66 & 3 & Palliative & 4 & Dead & $>$ I \\
\hline 67 & 3 & Palliative & 14 & Dead & $>$ I \\
\hline 68 & 3 & Palliative & 4 & Dead & $>$ I \\
\hline 69 & 3 & Palliative & 5 & Dead & $>\mathbf{I}$ \\
\hline 70 & 3 & Palliative & 4 & Dead & $>I$ \\
\hline
\end{tabular}

^Death unrelated to cancer; all other deaths due to tumour.

using the product limit method (Kaplan and Meier method). For comparison of survival curves the generalised Wilcoxon test and the log rank test (generalised Savage test) were used. Nine patients were censored because five were still alive and four had died of causes unrelated to cancer. Then in a multivariate approach the Wilcoxon test and the log rank test were used to assess the additive prognostic information of univariate significant covariates to the DNA typing. ${ }^{15} 16$ The test parameters were considered either as continuous (age) or categorical (type of surgery: radical $v$ palliative; tumour stage: I $v$ $>\mathrm{I}$; tumour localisation: head $v$ body and tail; 
TABLE II Association between surgical treatment, tumour stage, and the three DNA types (percentages in parentheses)

\begin{tabular}{cccccc}
\hline & \multicolumn{2}{l}{ Type of surgery } & \multicolumn{2}{l}{ Tumour stage } \\
\cline { 2 - 3 } \cline { 5 - 6 } & Radical & Palliative & & $I$ & $>I$ \\
\hline DNA & 7 & 1 & 2 & 6 \\
type 1 & $(87 \cdot 5)$ & $(12 \cdot 5)$ & & $(25 \cdot 0)$ & $(75 \cdot 0)$ \\
DNA & 17 & 18 & 7 & 28 \\
type 2 & $(48 \cdot 6)$ & $(51 \cdot 4)$ & & $(20 \cdot 0)$ & $(80 \cdot 0)$ \\
DNA & 7 & 20 & & 3 & 24 \\
type 3 & $(25 \cdot 9)$ & $(74 \cdot 1)$ & & $(11 \cdot 1)$ & $(88 \cdot 9)$ \\
& & $\mathrm{p}=0 \cdot 006^{\star}$ & & & $\mathrm{NS}^{\star}$
\end{tabular}

^Fisher's exact test (two tail). NS=not significant.

TABLE III Testing homogeneity of survival curves over strata

\begin{tabular}{lll}
\hline Strata & \multicolumn{2}{l}{$\begin{array}{l}\text { Wilcoxon test and Log rank test } \\
\left(\text { probability } \chi^{2}\right)\end{array}$} \\
\hline DNA type & 0.0004 & 0.0003 \\
Tumour stage & 0.0021 & 0.0006 \\
Type of surgery & 0.0012 & 0.0001 \\
Tumour localisation & NS & NS \\
Age & NS & NS \\
\hline
\end{tabular}

NS=not significant.

DNA type: $1 v 2 v 3$ ). The categorisation of DNA types was based on empirical reasoning in a modification of a classification used by Auer: due to the known low number of 'euploidy' in pancreatic cancer the original types I and II were calculated as one group (type 1) for statistical reasons. ${ }^{717}$ Likewise, the categorisation of type of surgery, tumour stage, and tumour localisation was based on earlier empirical results. ${ }^{18} 19$

\section{Results}

There was a significant correlation between the DNA type and the type of surgery performed on the primary tumour, whereas the tumour stage showed no significant correlation to the DNA type (Tables I and II). The survival curves differed significantly for DNA type, tumour stage, and type of surgery, while age at diagnosis and tumour localisation were not significantly correlated to prognosis (Table III). The survival probability was best for DNA type 1 patients $(n=8)$ followed by DNA type 2 patients $(n=35)$, while DNA type 3 patients $(n=27)$ had the poorest prognosis (Fig 2). Two of eight patients with DNA type 1 , three of 35 with DNA type 2, and none of 24 with DNA type 3 were alive at follow up (Table I). The covariant analysis showed that only the tumour stage remained significantly in the model, while the type of surgery did not add significant prognostic in-

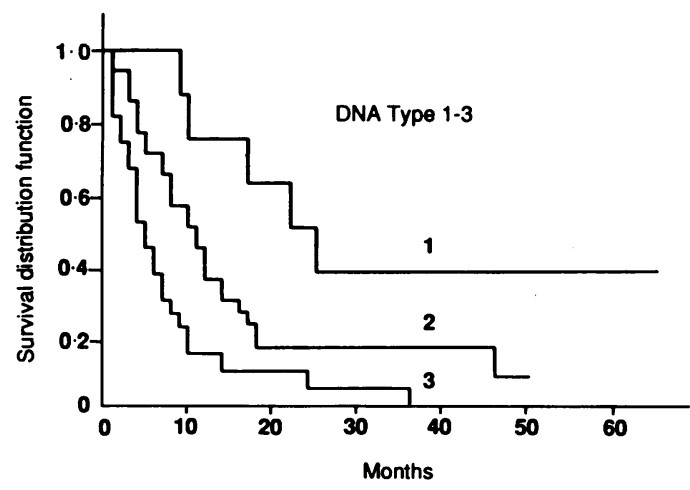

Figure 2: Survival function estimates in three DNA groups.
TABLE IV Rank tests for the association of response with covariates pooled over strata (DNA type)

\begin{tabular}{|c|c|c|}
\hline \multirow{2}{*}{$\begin{array}{l}\text { Covariates } \\
\text { Tumour stage } \\
\text { Type of surgery }\end{array}$} & \multicolumn{2}{|c|}{$\begin{array}{l}\text { Forward stepwise sequence of } \chi \\
\text { for the Wilcoxon test and log } \\
\text { rank test probability increment }\end{array}$} \\
\hline & $\begin{array}{l}0.0004 \\
\text { NS }\end{array}$ & $\begin{array}{l}0.0014 \\
\text { NS }\end{array}$ \\
\hline
\end{tabular}

formation (Table IV). Both variables, tumour stage and type of surgery, fitted for the covariant model having linear logarithmic survival curves $(\log (-\log )$ (estimated survival function)) against $\log$ (failure time)).

\section{Discussion}

The extremely poor prognosis for pancreatic cancer, despite remarkable diagnostic and therapeutic advances, has led many clinicians to question whether patients with pancreatic cancer should submit to radical surgery. ${ }^{20-23}$ Nevertheless, the only, though minimal, chance for longterm survival and cure is undoubtedly related to the feasibility of radical surgery. ${ }^{2+26}$ After radical resection over $90 \%$ of patients will develop local recurrence or distant metastases, and at most, $10 \%$ of all patients will survive more than five years.

Therefore, it would be of major clinical interest to be able to evaluate the aggressiveness of the single pancreatic cancer, the likelihood of radical resection, and the prognosis for each patient.

The technique of fine needle aspiration allows sampling of cellular material, before operation and intraoperatively, without requiring a surgical biopsy. The simplicity, speed, and patient acceptability of this technique allow tumour cells to be obtained from both operable and inoperable malignancies. The aspirated material seems to be highly representative of the cellular composition of the tumour, which is explained by the fact that the needle passes through the entire tumour mass, collecting cells from many parts of the tumour. ${ }^{17}$ Furthermore, only five of 75 cases had to be rejected from analysis due to the sparsity of cells. This is a better result than in earlier investigations by means of the disintegration technique of paraffin embedded tumour material, where almost $25 \%$ of cases had to be rejected due to preparation problems. ${ }^{27}$

The DNA histogram typing presented is a modification. The original typing used by Auer was established on breast cancer, where euploid tumours are represented in a large number of cases. ${ }^{9}$ From earlier studies we expected a majority of aneuploid cases and we therefore put the original types I and II together. ${ }^{27}$

It will be of interest to establish an index formula comprising a quantity of significant preoperative information - for example, the quantitative DNA content of tumour cells, ultrasound, and computed tomography - concerning the tumour, thereby possibly defining the small number of patients eligible for curative treatment. This, however, must be evaluated in a randomised prospective trial. If such information should prove reliable, adequate treatment could be given to patients. The present results 
show that, compared with the DNA content, only the tumour stage contributes important information on probable survival.

According to our findings there is a high correlation between local resectability of tumours and their quantitative DNA content. The intraoperative decision on the type of surgery, however, is strongly determined by tumour stage and local resectability. Therefore, a relation between the quantitative DNA content and tumour progression at diagnosis can be expected. This strongly suggests that the quantitative DNA content may provide important additional information preoperatively, and may help the surgeon to plan for radical or palliative surgery. A similar correlation has recently been found for breast cancer. ${ }^{28}$ Our results may provide a new indication for preoperative fine needle aspiration by adding essential prognostic information to any diagnostic means applied before laparotomy in patients eligible for radical surgery. ${ }^{29}$

This work was supported by grants from the Swedish Cancer Society, the Cancer Society of Stockholm, the King Gustaf V
Jubilee Fund, and the Faculty of Medicine at the Karolinska Institute.

1 Levin DL, Conelly RR, Devesa SS. Demographic characteristics of cancer of the pancreas. Mortality, incidence, survival. Cancer 1981; 47: 1456-68.

2 Gudjonsson B. Cancer of the pancreas, 50 years of surgery. Cancer 1987; 60: 2284-303.

3 Atkin NB, Kay R. Prognostic significance of modal DNA value and other factors in malignant tumors, based on 1465 value and other factors in malignant
cases. BrF Cancer 1979; 40: 210-21.

4 Boehm N, Sandritter W. DNA in human tumors: cytophotometric study. Curr Top Pathol 1975; 60: 151-219.

5 Atkin NB. Modal deoxyribonucleic acid value and survival in carcinoma of the breast. $B M F 1972$; i: $271-2$.

6 Zimmermann PV, Hawson GAT, Bint MH, Parsons PG. Ploidy as prognostic determinant in surgically treated lung cancer. Lancet 1987; ii: 530-3.

7 Weger AR, Schwab G, Kemmler G, et al. Quantitative DNA measurements in ductal pancreatic carcinoma: a comparison of the DNA content with histology, survival rate grading of the DNA content with histology, survival rate, grading 1987; 71: $190-2$.

8 Eneroth C-M, Zetterberg A. The relationship between the nuclear DNA content in smears of aspirates and the prognosis of mucoepidermoid carcinoma. Acta Otolaryngol (Stockh) of mucoepiderm
9 Fallenius AG, Auer GU, Carstensen JM. Prognostic significance of DNA measurement in 409 consecutive breast cancer patients. Cancer 1988; 62: 331-41.

10 UICC: International Union Against Cancer. TNM classification of malignant tumors. 5th ed. Geneva: UICC, 1987.

11 Gaub J, Auer G, Zetterberg A. Quantitative cytochemical aspects of a combined Feulgen naphthol yellow $S$ staining procedure for simultaneous determination of nuclear and cytoplasmatic proteins and DNA in mammalian cells. Exp Cell Res 1975; 92: 323-32.

12 Azavedo E, Tribukait B, Konaka C, Auer G. Reproducibility of the cellular DNA distribution pattern in multiple fine-needle aspirates from human malignant tumours. fine-needle aspirates $1982 ; 90: 79-83$.

13 Fallenius A, Askensten U, Skoog L, Auer G. The reproducibility of microspectro-photometric and flow cytometric nuclear DNA measurements in adenocarcinoma of the breast. Cytometry 1987; 8: 260-6.

14 Kendall M, Stuart A. The advanced theory of statistics. Vol 2. New York: Macmillan, 1979: 580-8.

15 Kalbfleisch JD, Prentice RL. The statistical analysis of failure time data. New York: John Wiley, 1980.

16 Mantel N. Evaluation of survival data and two new rank order statistics arising in its consideration. Cancer Chemotherapy Reports 1966; 50: 163-70

17 Auer GU, Caspersson TO, Wallgren AS. DNA content and survival in mammary carcinoma. Anal Quant Cytol 1980; 2: surviva.

18 Hermanek AS, Thomas CY, Friesen SR. Importance of pathological staging in the surgical management of the pathological staging in the surgical managem

19 Moossa AR. Pancreatic cancer, approach to diagnosis, selection for surgery and choice of operation. Cancer 1982; 50: 2689-98.

20 Shapiro TM. Adenocarcinomas of the pancreas: a statistical analysis of biliary bypass vs Whipple resection in good risk patients. Ann Surg 1975; 6: 715-21.

21 Crile GJ. The advantages of bypass operations over radical pancreatecto-duodenectomy in the treatment of pancreatic carcinoma. Surg Gynecol Obstet 1970; 130: 1049-53.

22 Lund F. Carcinoma of the pancreas: palliation or radical surgery. Acta Chir Scand 1986; 134: 461-7.

23 Lea MS, Stahlgren LRH. Is resection appropriate for adenocarcinoma of the pancreas? Am $\mathcal{F}$ Surg 1987; 154: 651-3.

24 Fortner JG. Surgical principles for pancreatic cancer. Regional total and subtotal pancreatectomy. Cancer $1981 ; 47$ : 1712-8.

25 Fortner JG. Regional pancreatectomy for cancer of the pancreas, ampulla and other related sites. Tumor staging and results. Ann Surg 1984; 199: 418-26.

26 Ihse J, Lilja P, Arnesjo B, Bengmark S. Total pancreatectomy for cancer appraisal of 65 cases. Ann Surg 1977; 186: 675-80.

27 Weger AR, Mikuz G, Askensten U, Auer GU, Schwab G, Glaser KS. Methodological aspects of DNA image cytometry in formalin fixed paraffin embedded material from pancreatic adenocarcinoma. Pathol Res Pract 1989; 185: $752-4$.

28 Falkmer UG, Hagmer T, Auer GU. Efficacy of combined image and flow cytometric DNA assessments in human breast cancers. A methodologic study based on a routine histologic material of 2024 excised tumor specimens. Analytical Cellular Pathology (in press).

29 Glaser KS, Weger AR, Schmid KW, Bodner E. Is fine-needle aspiration of tumours harmless? Lancet 1989; i: 620 